\title{
Comunidade de práticas: revisão sistemática em prol das bibliotecas públicas
}

\author{
Community of practice: systematic review in favor of public libraries
}

\begin{abstract}
Daniele Achilles
Doutora em Memória Social pelo Programa de Pós-Graduação em Memória Social pela Universidade Federal do Estado do Rio de Janeiro - UNIRIO, Brasil. Professora do Departamento de Biblioteconomia da Universidade Federal do Estado do Rio de Janeiro UNIRIO, Brasil. daniele.achilles@unirio.br
\end{abstract}

\author{
Alex Medeiros Kornalewski \\ Pós-doutorando do Programa de Pós-Graduação em Memória Social Universidade Federal do Estado do Rio de \\ Janeiro - UNIRIO, Brasil. \\ E-mail: alexmedeiros87@ hotmail.com
}

\section{Resumo}

No contexto atual, marcado por uma crise sanitária, produção e disseminação cada vez mais rápida da informação e do conhecimento, tornam-se mais urgente as bibliotecas públicas se adaptarem aos novos desafios impostos tecido social. Nesse sentido, a escassez de recursos financeiros e materiais, bem como a carência de políticas públicas, dentre outros fatores, vem acelerando o sucateamento dessas instituições que direcionam suas ações para a educação, cultura, lazer, memória. Esse artigo tem como objetivo discorrer sobre a importância da metodologia comunidade de práticas, destacando possibilidades de gestão colaborativa. E, para tal, apresenta um percurso conceitual e aplicações voltadas ao provimento de recursos inerentes à tomada de decisão nos fazeres das bibliotecas públicas, da Rede de Bibliotecas Populares de Niterói, do estado do Rio de Janeiro. Desse modo, o caminho metodológico se definiu a partir da revisão sistemática sobre o conceito comunidade de práticas, subsidiando a compreensão teórica e prática dos fazeres biblioteconômicos nessas instituições e direcionando a construção de boas práticas, o que auxilia em certa medida o reconhecimento e a ressonância social dessas bibliotecas. Conclui-se a urgência de empreendimentos que adotem o processo dialógico, o intercâmbio de experiências, a ressonância junto à sociedade e o engajamento de setores como as universidades e o Estado, convertendo-se em fatores essenciais à manutenção, atuação e desenvolvimento das bibliotecas públicas.

Palavras-Chave: Biblioteconomia. Bibliotecas públicas. Comunidade de práticas. Comunidade de práticas experiências. Comunidade de Práticas - intercâmbio de informações.

\begin{abstract}
In the current context, marked by a health crisis, production and increasingly rapid dissemination of information and knowledge, it becomes more urgent for public libraries to adapt to the new challenges imposed on the social fabric. In the sense, the scarcity of financial and material resources, the lack public policies, among other factors, are accelerating the scrapping of these institutions that direct their actions towards education, culture, leisure, memory. This article aims to discuss the importance of the community of practices (COP's) methodology. And, for that, it presents a conceptual path and applications animed at providing resources in herent to decision making in the making of public libraries, the network of Popular Libraries of Niterói, in the state of Rio de Janeiro. In this way, the methodological path was defined from the sustematic review of the COP's subsidizing the theoretical and practical understanding of library activities in these institutions and directing the construction of good practices, which helps in the recognition and social resonance of these libraries. It concludes the urgency of in der takings that adopt the dialogical process, the Exchange of experiences, the resonance with society and the engagement of sectors such as universities and the State, becoming essential factors for the maintenance, performance and development of public libraries.
\end{abstract}

Keywords: Library science. Public libraries. Community of practices. Community of practices - experience. Community of practices - exchange and information.

Bibl. Esc. em R., Ribeirão Preto, v. 7, n. 2, p. 141-162, 2021.

DOI: 10.11606/issn.2238-5894.berev.2021.184383 


\section{Introdução}

Diante das transformações impulsionadas pelo capitalismo, globalização e uso massivo das tecnologias, a rapidez dos processos que impactam os modos de vida tem corroborado para um movimento excessivo de compartilhamento de dados em detrimento da pouca assimilação, construção, organização e, até mesmo reflexão.

Em virtude disso, mudanças no âmbito da comunicação e informação passaram a gerar novas formas de produção, acesso e uso da informação e do conhecimento. O que afetou os modos de construção da vida dos sujeitos e as práticas das organizações sociais. Nesse contexto, este artigo alerta para o papel desempenhado pelas bibliotecas públicas na atualidade.

As bibliotecas públicas sempre estiveram condicionadas aos entraves e dificuldades de ordem estrutural, assim como à falta de recursos. Sem contar com inúmeros percalços que geram limitações estruturais e, de ordem teórico-prática, tais como atuação isolada das bibliotecas. Por serem instituições essenciais para dirimir as iniqüidades sociais e informacionais existentes, ainda, no Brasil, existe uma balança desfavorável entre classes sociais, as que possuem um grau de acesso à informação, enquanto outras passam por uma situação de infoexclusão (VAZ, 2020).

A investigação sobre o conceito "comunidade de práticas" teve como mote apresentar como essa metodologia pode servir à compreensão de problemas e dificuldades inerentes às bibliotecas públicas. Para avançar, as bibliotecas públicas carecem de fortalecer-se buscando uma rede de apoio, por meio do intercâmbio de informações e experiências.

Com a intenção de produzir uma reflexão sobre o conceito, aplicações e metodologia sobre as COP's, a pesquisa se desenvolveu a partir de uma revisão sistemática, com natureza exploratória que exibe o conceito-chave "comunidade de práticas" e correlaciona-o ao ambiente da biblioteca pública. Assim, foram adotadas estratégias de busca utilizando as bases de dados BRAPCI, Capes e Scielo. Ademais, o levantamento bibliográfico tem elo com o campo empírico, uma vez que a necessidade da revisão sistemática ocorreu em virtude de compreender como as ações extensionistas poderiam se desenvolver a partir da aplicação da metodologia das COP's.

O projeto de extensão, realizado em parceria com a Rede de Bibliotecas Populares do Município de Niterói, no Estado do Rio de Janeiro, deu origem a este artigo tinha como objetivo 
traçar ações e promover práticas no âmbito da Biblioteconomia Pública e da Memória, visando a construção de conhecimento por intermédio das experiências de profissionais envolvidos com as atividades e dinâmicas de construção desse tipo de biblioteca (ACHILLES, 2018a, p. 1).

Quanto ao escopo, o projeto propiciou a construção e manutenção de uma cultura pautada no processo dialógico (BUBER, 2014), levando em consideração a interdisciplinaridade - compreendida como um movimento que "coloca em xeque a disjunção entre as disciplinas, valorizando pesquisas capazes de atravessar os domínios separados" (GONDAR, 2016, p. 22). Em aditamento, articulou o ensino, pesquisa e extensão, e promoveu, em certo sentido, o impacto social com vistas às ações desenvolvidas no domínio proposto.

O reconhecimento da realidade vivida pelas bibliotecas públicas da rede foi essencial para iniciar a interação dialógica e, ao longo do tempo, implementar a metodologia comunidade de práticas, o que justifica o desenvolvimento do estudo aqui proposto.

De posse das informações supracitadas, a estrutura adotada revela o modo como as bibliotecas públicas vêm se definindo a partir a existência e invisibilidade. Isso significa que, para distanciar de tal situação focalizamos as comunidades de práticas, como metodologia em prol do fortalecimento das bibliotecas públicas por intermédio de cinco propostas teóricoargumentativas são elas: 1) apresentação da temática a ser discutida ressaltando a importância do entrelaçamento da biblioteca pública com o desenvolvimento da COP aplicada a essa conjuntura específica; 2) exposição do aporte teórico sobre biblioteca pública, com foco nos dados que versam sobre a Rede de Niterói; 3) compilação e apresentação dos dados relativos ao desenvolvimento elementar o conceito, a partir da revisão sistemática (aplicada nas bases de dados Brapci, Capes e Scielo), a síntese e interpretação dos dados recuperados; d) apresentação da Rede de bibliotecas de Niterói, desvelando suas necessidades e pontos a serem discutidos, por intermédio do intercâmbio de experiências, instrumentalizado pela COP; e) Considerações parciais e possíveis sobre a pesquisa, apontamentos reflexivos sobre os caminhos que se cruzam entre a teoria e a prática, com a finalidade de fomentar novas pesquisas. Dessa maneira, foi possível alinhar teoria e prática, considerando a experiência extensionista (campo empírico) à revisão sistemática (campo teórico) e compor este artigo. 


\section{Bibliotecas públicas}

Segundo o Sistema Nacional de Bibliotecas Públicas (SNBP), o país conta com $6.057^{1}$ bibliotecas públicas federais, estaduais e municipais. No entanto, se tornaram invisíveis aos 'olhos' da sociedade brasileira. A diversidade de transformações, ocorridas nas últimas décadas, em virtude do capitalismo e da globalização, aceleraram esse processo de invisibilidade, possibilitando novas demandas no que tange a produção, o acesso e uso da informação e do conhecimento.

Os problemas inerentes às bibliotecas públicas brasileiras não se colocam apenas na atualidade. Principalmente no que tange o conceito, observamos o conceito é sempre uma produção, uma representação dos usos e aplicações. Moscovici (2010, p. 46) complementa ao descrever sobre as representações sociais como "uma maneira específica de compreender e comunicar o que nós já sabemos [...] tem como seu objetivo abstrair sentido do mundo e introduzir nele ordem e percepções, que reproduzem o mundo de uma forma significativa". Logo, se averigua que os conceitos são representações do social cuja interligação entre o seu viés de "tradução do mundo" em consonância com sua ação, seu uso, estabelecem uma ponte necessária para estabelecer avanços ímpares às bibliotecas públicas.

Todavia, no Brasil, por exemplo, conforme aponta Achilles (2018), as bibliotecas públicas vêm enfrentando uma crise que se incide na representação identitária desse tipo de instituição frente às demandas sociais. Essa crise revela uma falta de aderência e ressonância social das bibliotecas pública perante a sociedade e, consequentemente, evidencia uma desconexão entre a dimensão teórica e a dimensão prática desde muito tempo. É mister, a partir de uma breve explanação, que a tríade (missão, visão e valores) compõem a formação, a essência de qualquer instituição: A missão é definida como a "razão de ser", o que possibilita a existência em si da instituição e, por conseguinte, seu respectivo papel junto à sociedade; a visão, evoca a imagem externa da instituição, o que se almeja, fornece subsídios para pensar o futuro esperado, ou seja, remete ao planejamento do porvir (CARIBE, 2017; KORNALEWSKI; FARIAS, 2019). Em aditamento, os valores são os princípios norteadores da instituição, determina "como as pessoas trabalham para realizar a visão" (CARIBE, 2017, p. 195).

\footnotetext{
${ }^{1}$ Dado divulgado pelo Sistema Nacional de Bibliotecas Públicas. Disponível em: http://snbp.cultura.gov.br/bibliotecaspublicas/. Acesso em: 04 mar. 2020.
} 
A tríade citada interfere tanto na dimensão teórica quanto na prática, sendo que a inexistência de compreensão quanto a missão, ausência de visão e valores de uma determinada biblioteca pode acarretar em uma série de problemas para a práxis biblioteconômica e, ainda, diversos prejuízos sociais, tais como: ausência de profissionais - ou treinamentos - essenciais para o exercício das funções biblioteconômicas, falta de estudo de usuários aplicado em prol da dúplice usuário real e usuário potencial, ausência ou defasagem de políticas de desenvolvimento de coleções, não acompanhamento de necessidades de informação básicas aos integrantes da comunidade ao redor da biblioteca e afins (SOARES et al., 2019).

A lógica de funcionamento das bibliotecas depende diretamente da funcionalidade que a sociedade confere a elas, fazendo emergir algum elemento característico de sua identidade institucional ligada diretamente a alguma função ou uso. Como aponta Escolar (1990, p. 404), as bibliotecas públicas deveriam reunir materiais e dar suporte a formação profissional e moral, além de exercer a função recreativa. Mueller (1984, p. 9) afirma que, sob a influência de ideias liberais e pelo pensamento utilitário de autoajuda, as bibliotecas públicas eram vistas como um bom investimento social e deveriam fornecer prazeres inocentes aos homens exaustos e sem dinheiro, isto é, servia como uma instituição que poderia conter as massas. Ademais, deveriam incentivar o gosto pela leitura e contribuir com o processo civilizatório. Isto é, participar do processo de organização social.

Alfaro López (2010, p. 18) alertou para importância da biblioteca como uma instituição voltada para a transformação social. Bibliotecas públicas como instituições em prol de um bem maior conduz, talvez, a incorporação de valores, mediado pelas estruturas de poder e, desconsidera, de certo modo, seus usos efetivos. Segundo uma das máximas da Biblioteconomia, a razão de ser de uma biblioteca é o seu usuário. Desse modo, surge o seguinte questionamento: de que modo as bibliotecas públicas foram construindo o seu conceito ou agregando elementos conceituais tendo como referência a comunidade de usuários?

Esse questionamento ilustra bem as colocações de Alfaro López (2008; 2010) sobre as bibliotecas públicas. O teórico afirma que a biblioteca havia vivido uma grande magnitude que empreendeu a biblioteca pública a partir da segunda metade do século XIX, principalmente nos Estados Unidos. As necessidades da comunidade eram satisfeitas e geravam instrumentos biblioteconômicos para produzir a expansão e o crescimento dessas instituições. Todavia, o autor denuncia uma espécie de desconexão entre duas dimensões: a teórica e a prática, que se 
converteu em um problema, até mesmo, para formalizar uma parte da própria ciência Biblioteconomia.

Alfaro López (2008, p. 1) enfatiza "La biblioteca no nos há dejado pensar La Biblioteca", isto é, através da diferenciação semântica entre biblioteca (com "b" minúsculo) e Biblioteca (com "B" maiúsculo) se localiza uma barreira que nos impede a elaboração conceitual da Biblioteca. Isto é: a biblioteca se converteu em um obstáculo epistemológico que implica na construção teórica da Biblioteca. Ou seja, uma desconexão entre a dimensão teórica e prática que se apresenta no processo do conhecimento, como alerta Alfaro López (2010, p.5).A desconexão alertada por Alfaro López (2008; 2010) é reafirmada por Achilles (2018), quando define a biblioteca pública como um espaço de experiência, e conjectura que a formação do entendimento conceitual relativos a essas instituições deve ser aberta, isso porque são as práticas que fundamentam os conceitos teóricos.

\section{Comunidade de práticas}

O conceito Comunidade de Práticas (COP's) está relacionado à aprendizagem humana e parte da ideia social para aprendizagem, isso porque se fundamenta em teorias da Antropologia e da Teoria Social. O termo cunhado por EtienneWenger (2010) se dedica as pesquisas em teoria da aprendizagem, relacionando-o à aprendizagem humana porque, conforme sua visão, depende das relações sociais, da própria aprendizagem e dimensões, o que configura um sistema de aprendizagem social.

Se o conceito se baseia em dois pilares: relações sociais e aprendizagem, isso significa que pessoas reunidas e que formam determinados grupos sociais fazem isso porque compartilham interesses em comuns, possibilitando a troca de informações, bem como a construção do conhecimento individual e coletivo. Esse processo fomenta a estruturação da comunidade e sua manutenção, além do compartilhamento dos diferentes tipos de aprendizado.Podemos inferir que o método 'comunidade de práticas' se baseia no próprio processo de ensino-aprendizagem. E tem como referência os processos de troca, de intercâmbio de experiências e vivências teórico-práticas.

Para Wenger (2010) o aprendizado inerente às comunidades de práticas apresenta as seguintes dimensões: empreendimento conjunto; envolvimento mútuo; repertório 
compartilhado. As dimensões são indispensáveis porque os sujeitos de um grupo com interesses em comum se mantêm em interação constante e geram novas informações e conhecimentos.

Diante da exposição conceitual inicial, foi verificado a insurgência de inúmeros modelos conceituais e práticas distintas que tomam por base o modelo de COP`s. Assim sendo, é mister o desenvolvimento de uma revisão sistemática, em prol de compreender a cobertura da literatura e os respectivos usos do instrumento de COP`s. Para tal, alguns critérios são basilares para o desenvolvimento da revisão sistemática: apresentar o protocolo de pesquisa; a pesquisa deve apresentar a condição de reprodutibilidade; apresentar as bases de dados utilizadas; apresentar as estratégias de busca utilizadas em cada base de dados; discorrer sobre o processo de seleção dos artigos científicos; apresentar os critérios de inclusão, ou exclusão dos artigos; apresentar as limitações dos artigos escolhidos; apresentar as limitações da própria revisão sistemática e descrever a análise feita a partir da revisão sistemática (GALVÃO; RICARTE, 2019).

Na primeira etapa, o protocolo de pesquisa, foram empregados os preceitos da estratégia de busca por intermédio da pesquisa com operadores booleanos (AND, OR, NOT) em prol de construir entrelaçamentos e, por conseguinte, profundidade, na pesquisa em bases de dados. Para fins de esclarecimento, a estratégia de busca envolve quatro fatores: primeiro, é utilizado uma linguagem natural ou sistemática para o início da pesquisa. Nesse ponto, a pesquisa se iniciou pela "pérola de citação", ou seja, o uso de um termo basilar, no caso o conceito de “comunidade de práticas". O uso da "pérola de citação" serve para conduzir a pesquisa na busca de outros termos, oriundos de linguagem natural ou não, de forma a prover "o crescimento do resultado de busca" (LOPES, 2002, p. 66). O segundo fator é a construção do vocabulário de busca (construído a partir do resultado de termos obtidos pela "pérola de citação"). O terceiro fator é a elaboração das estratégias de busca combinadas com os operadores booleanos citados. O quarto fator necessário no protocolo de pesquisa é a análise do resultado propriamente dito.

Para o desenvolvimento da primeira etapa supracitada, é necessário apresentar as bases de dados adotadas na presente pesquisa (segunda etapa), bem como suas condições de reprodutibilidade (terceira etapa). Foram adotadas três bases de dados: Brapci, Capes e Scielo. O critério de adoção das bases se deu pelos seguintes pontos: a base de dados Brapci aloca uma literatura científica especializada no campo da Ciência da Informação, Biblioteconomia, Museologia, Arquivologia e demais artigos inerentes as discussões da informação. A Capes foi considerada pela abrangência em nível nacional e a Scielo foi adotada por conta de sua abrangência e visibilidade internacional. 
A quarta etapa consiste na validação dos critérios de reprodutibilidade, ou seja, é mister o máximo de transparência quanto aos detalhes do desenvolvimento da pesquisa e as estratégias de busca que foram adotadas. O recorte temporal empregado nas bases de dados remete aos últimos 10 anos, no intuito de recuperar apenas a literatura recente sobre o conceito comunidade de práticas. Em consonância, a quinta etapa implica na explicitação dos critérios de inclusão e seleção dos artigos. Ambas as etapas serão discutidas de forma conjunta na análise da recuperação dos artigos, nas bases de dados abaixo.

Na base de dados Brapci, a pesquisa se utilizou apenas da pérola de citação, tendo em vista a especificidade do portal. Nessa base foram recuperados 98 itens no período de 20102020. Na base em questão, 12 itens possuem relevância dentro das discussões de comunidade de práticas. Os demais artigos foram descartados pois não apresentaram nenhum dos seguintes pontos: discussão teórica sobre o conceito de comunidade de práticas; estudo empírico; uso de termos separados ("comunidade" ou "prática") de forma a representar itens não relevantes para o presente estudo; uso do conceito comunidades de práticas dissociado com os pressupostos básicos descritos pelo percussor do conceito e, por conseguinte, prática desse modelo de interação e aprendizagem (WENGER, 2010).

Na base de dados da Capes, a pesquisa utilizou a pérola de citação "comunidade de práticas", porém aplicou termos complementares, para gerar especificidade na busca, tendo em vista a grande abrangência da base. Eis a estratégia de busca final aplicada na respectiva base de dados: "comunidade de práticas" AND biblioteca OR arquivo OR conhecimento. A escolha dos termos complementares se deu pela recuperação dos mesmos a partir da busca realizada somente com a pérola de citação e pelo uso recorrente desses termos na literatura que versa sobre a temática em questão. Foram recuperados 15 itens no mesmo recorte temporal da base anterior. Contudo, um terço dos itens foi categorizado como relevantes dentro dos mesmos critérios adotados no processo de seleção da base de dados anterior.

Na base de dados Scielo, a pesquisa também aplicou a pérola de citação comunidade práticas, porém não houve necessidade de colocar em aspas, pois a plataforma já identificou, no processo de busca, como um conceito composto. Em aditamento, também foi necessário aplicar termos complementares, para tornar a busca especifica, tendo em vista a visibilidade de âmbito internacional da base. Segue a estratégia de busca final na presente base: comunidade práticas AND (biblioteca OR informação OR conhecimento OR arquivo OR documento). O critério de escolha dos termos complementares segue o já disposto na base de dados anterior. 
Foram recuperados 175 itens no mesmo recorte temporal das bases anteriores. Todavia, apenas 3 itens foram categorizados como relevantes, tomando como base os critérios de seleção também aplicado as bases Brapci e Capes.

Diante do exposto, cabe explicitar a sexta etapa, que versa sobre o processo de seleção dos artigos, sendo a mesma compreendida por intermédio de 4 pontos. Primeiro, a leitura dos títulos; segundo a leitura dos resumos; terceiro a leitura das palavras-chave; quarto a leitura do texto completo. O processo de seleção só permitiu a exclusão a partir da leitura do texto completo nas bases de dados Brapci e Capes. A grande maioria dos itens localizados na Base de dados Scielo foram excluídos a partir da leitura dos três primeiros pontos (título, resumo e palavra-chave). Além disso, os 3 itens relevantes que foram recuperados na base de dados Scielo também eram duplicatas, com base no que foi recuperado na base de dados Capes, portanto, não houve itens finais recuperados na base Scielo para somar a revisão sistemática proposta. Essas duplicatas são: Fartes (2014), Freitag e Santos (2013), localizados na Scielo e Capes, e Silva et al. (2012), localizado na base de dados Brapci e Scielo. Após a exposição da estrutura adotada na revisão sistemática, é mister estabelecer breves apontamentos sobre os artigos relevantes recuperados na base de dados Brapci e Capes.

Dos artigos recuperados na base de dados Brapci, iniciamos com o texto das autoras Rimá, Garcia e Targino (2017). Ele apresenta três pontos fortes: O desenvolvimento teórico explicitado se fundamenta nos pressupostos pioneiros de Wenger (2010), de forma a endossar a perspectiva da aprendizagem como uma ação interligada com o mundo, portanto, uma prática social. Segundo, as autoras adentram a partir dessa definição nos elementos que fundamentam sua discussão da comunidade virtual como algo que segue as diretrizes da comunidade de práticas. Terceiro, discorrem sobre por intermédio de um estudo de caso para ilustrar as respectivas fundamentações. Contudo, um limitador é a ausência de discussão teórica que interligue os pressupostos teóricos da comunidade de práticas com o viés da comunidade de práticas virtuais, de forma que o aporte teórico se mostra eficaz unicamente no contexto de apresentação do que se trata COP's. Avigora-se que a limitação discutida diz respeito exclusivamente com as questões inerentes ao que a presente pesquisa busca (percurso conceitual e aplicabilidade das COP's) e não a limitações dos artigos em si.

O segundo artigo analisado tem por autoria Schmitt e Pacheco (2016). O artigo apresenta os seguintes pontos fortes para a presente investigação: primeiro, interliga a discussão das COP’s com as implicações conceituais da gestão do conhecimento (GC); segundo, abrange 
uma fundamentação teórica para além da abordagem de Wenger (2010) e avigora que as COP's mais do que um modelo de aprendizagem social, também se aplicam no compartilhamento dos desconhecimentos; terceiro, apresenta diferenciação teórica entre os modelos de COP’s, grupo de trabalho formal, equipe de projeto e rede informal; quarto, apresenta estudo de caso "Aluno integrado", este sendo um projeto participante do Programa Nacional de Formação Continuada em Tecnologia Educacional (Proinfo Integrado).

O terceiro artigo de autoria de Sarruf e Silva (2012), apresenta os seguintes pontos: fundamentação teórica sobre COP's e COP's virtuais aplicada a gestão do conhecimento de viés organizacional; segundo, apresenta estudos de casos diversos em empresas. Contudo, averígua-se uma limitação em comparação com a literatura de Schmitt e Pacheco (2016) que diferencia COP’s de redes informais, enquanto essa diferenciação não é discutida no texto de Sarruf e Silva, descrita em sinonímia com as redes informais.

O quarto artigo recuperado na Brapci, Fernandes et al. (2016) apresenta os seguintes pontos: reforça os pressupostos teóricos descritos na análise do artigo anterior; segundo, disserta sobre os estágios de desenvolvimento de uma COP, sendo: potencial, união, madura, ativa, dispersa; terceiro, destaca os benefícios a curto e longo prazo; quarto, apresenta uma revisão sistemática feita em base de dados internacionais (Scopus, Science Directe, Web of Science).

O quinto artigo de Silva et al (2012) dá visibilidade aos seguintes aspectos: primeiro, estabelece uma relação da COP’s com o conceito de inteligência coletiva de Pierre Levy (1999) e as implicações conceituais da gestão do conhecimento; segundo, discute a diferenciação conceitual entre comunidade, comunidade virtual e comunidade de prática virtual; terceiro, apresenta dois estudos de casos ligados a própria área de biblioteconomia (caso Bibliocontas e fóruns de discussão).

O sexto artigo de Cornélio, Abreu, Costa (2010) disserta sobre os seguintes pontos: primeiro, endossa a relação das COP's com a gestão do conhecimento; segundo, discute COP's a partir da relação entre universidade e empresa por intermédio da comunidade de práticas em ambiente presencial e virtual; apresenta um modelo de COP relacional no qual as universidades entram como instituições de suporte, de acordo com as demandas das respectivas empresas, ao mesmo tempo em que o exercício das comunidades de práticas é crucial para os pesquisadores atrelados aos temas debatidos. Em suma, há um processo dialógico no qual a instituição suporte 
também recebe feedback por parte das instituições privadas, em prol do desenvolvimento de pesquisas nas universidades.

O sétimo artigo recuperado de autoria do Wilbert et al. (2017) promove as seguintes questões: relação da COP's com as discussões da gestão do conhecimento; apresenta aplicação do modelo de COP's virtuais em prol de inovações em instituições públicas; demonstra o uso do questionário semiestruturado, como instrumento basilar de coleta de dados para o exercício das atividades inerentes a COP. Contudo, a discussão sobre o conceito de inovação apresentado no texto não é discutida o que se mostra como uma limitação, tendo em vista que os autores apresentam a COP's como um modelo de aprendizagem social em prol da inovação.

O oitavo artigo de Lira, Araújo e Duarte (2017) também interliga o conceito de COP’s com a gestão do conhecimento, além dos seguintes aspectos: promoção de um estudo de plano piloto ao descrever a construção de uma COP nas unidades de contabilidade das universidades públicas; revisão de literatura que abrange o período de 2004 a 2016; estudo de caso próprio no setor de contabilidade da UFPB. Contudo, há uma limitação, haja vista que o próprio conceito de COP não apresenta uma explicitação basilar, seja na fundamentação teórica ou mesmo nas referências do respectivo estudo, o que inviabiliza nossa análise quanto a possibilidade de uma construção singular do conceito pelo artigo supracitado.

O nono artigo, dos autores Wilbert, Dandolini e Steil (2018), evidencia os seguintes pontos: relação da COP’s com a gestão do conhecimento; apresenta uma revisão sistemática na base de dados internacional Scopus; desenvolve as diversas áreas do conhecimento que aplicam o conceito de COP's (Ciências Sociais é apresentada como a principal, ao adotar $40 \%$ das citações recuperadas pelo autor). Apesardos autores apresentarem o conceito de COP's interligado a gestão organizacional, os mesmos não apresentam um estudo de caso, o que limita o resultado da pesquisa presente.

O décimo artigo remete a Souza e Souza (2019) e dá visibilidade a COP’s nos seguintes apontamentos: relação da COP com a gestão do conhecimento; destrincha a COP sob três fatores: domínio de um conhecimento, a comunidade em si e a prática de intercâmbio de experiências; discorre sobre três problemas que afetam as COP's: falta de tempo e desinteresse no compartilhamento de conhecimentos, baixa adesão dos temas trabalhados e falta de reconhecimento da própria COP’s. Apresenta estudo de caso em uma empresa de óleo, gás natural e energia (não cita a instituição). 
O décimo primeiro artigo de Melo, Moraes e Costa (2019), desenvolve os seguintes pontos: discute a relação do conceito de COP’s a gestão do conhecimento; adota estudo de caso dentro da área de biblioteconomia (Rede de Bibliotecas e Centros de Informação em Arte do Estado do Rio de Janeiro - REDARTE/RJ); concorda com os fatores apresentados por Souza e Souza (2019) quanto à estrutura de uma COP: domínio de um conhecimento, a comunidade em si e a prática de intercâmbio de experiências; apresentam o resultado do estudo de caso, por intermédio da investigação de 14 indicadores inerentes a uma estrutura de COP, segundo Wenger (1998) sendo elas:

1. As relações mútuas sustentáveis - harmoniosas ou conflituosas;

2. Formas compartilhadas de engajar-se em fazer as coisas juntos;

3. O rápido fluxo de informações e propagação da inovação;

4. Ausência de preâmbulos introdutórios, como se conversas e interações foram apenas a continuação de um processo contínuo;

5. Configuração muito rápida de um problema a ser discutido;

6. Sobreposição substancial entre as descrições de quem pertence dos participantes;

7. Conhecer o que os outros sabem o que eles podem fazer, e como eles podem contribuir para uma empresa;

8. Identidades mutuamente definidoras;

9. A capacidade de avaliar a adequação das ações e produtos;

10. Ferramentas específicas, representações e outros artefatos;

11. A sabedoria local, histórias compartilhadas, piadas, sabendo riso;

12. Jargão e atalhos para as comunicações, bem como a facilidade de produzir novos;

13. Certos estilos reconhecidos como a indicação de membros;

14. Um discurso compartilhado refletindo certa perspectiva sobre o mundo.

O décimo segundo artigo pertence aos autores Tavares, Ribeiro e Fioro (2011). Os mesmos adotam os seguintes pontos: relação da COP's com a gestão do conhecimento; apresentam estudo de caso (portal institucional OTICS); também apresentam o ciclo de vida das COP's (potencial, união, madura, ativa, dispersa); discute a diferenciação conceitual entre COP's e COP's virtual. 
Para fins de síntese do resultado recuperado na base de dados Brapci, segue um quadro resumo (tabela 1) com os seguintes pontos organizados: autoria, data da publicação (do mais antigo, 2010 para o mais recente, 2019), definição de COP’s apresentada pelos autores, quantitativo de estudo de casos apresentados (se houver), pontos fortes (quantitativo) e limitações (quantitativo). Vale ressaltar que os pontos fortes e limitações se aplicam de acordo com o objetivo da presente análise e não quanto a literatura científica pesquisada. Portanto, artigos que apresentaram aspectos que acrescentam ou aplicam novos olhares a COP's foram categorizadas como pontos fortes para a nossa pesquisa, enquanto artigos que não apresentaram as condições citadas para o viés investigativo que o texto presente objetiva, foram categorizados como limitações.

Tabela 1 - síntese da revisão sistemática sobre Comunidade de práticas - base de dados Brapci.

\begin{tabular}{|c|c|c|c|c|c|}
\hline Autor & $\begin{array}{l}\text { Data da } \\
\text { publicação }\end{array}$ & Definição de COP's & $\begin{array}{l}\text { Estudo } \\
\text { de caso } \\
\text { (quant.) }\end{array}$ & $\begin{array}{l}\text { Pontos } \\
\text { fortes } \\
\text { (quant.) }\end{array}$ & $\begin{array}{l}\text { Limitações } \\
\text { (quant.) }\end{array}$ \\
\hline $\begin{array}{l}\text { 1. Cornélio, } \\
\text { Abreu e } \\
\text { Costa }\end{array}$ & 2010 & $\begin{array}{l}\text { Aprendizagem social por intermédio da } \\
\text { relação universidade e instituições privadas. }\end{array}$ & 1 & 3 & 0 \\
\hline $\begin{array}{l}\text { 2. Tavares, } \\
\text { Ribeiro e } \\
\text { Fiorio }\end{array}$ & 2011 & $\begin{array}{l}\text { Aprendizagem como uma ação interligada } \\
\text { com o mundo, portanto, uma prática social. }\end{array}$ & 1 & 4 & 0 \\
\hline $\begin{array}{l}\text { 3. Sarruf e } \\
\text { Silva }\end{array}$ & 2012 & $\begin{array}{l}\text { COP's e COPs virtuais como modelo de } \\
\text { aprendizagem aplicado as organizações. }\end{array}$ & 3 & 2 & 1 \\
\hline $\begin{array}{l}\text { 4. Silva et } \\
\text { al. }\end{array}$ & 2012 & $\begin{array}{l}\text { Aprendizagem social como meio de } \\
\text { aprimoramento da inteligência coletiva. }\end{array}$ & 2 & 3 & 0 \\
\hline $\begin{array}{l}\text { 5. Schmitt e } \\
\text { Pacheco }\end{array}$ & 2016 & $\begin{array}{l}\text { Modelo de aprendizagem social e } \\
\text { compartilhamento de desconhecimentos, em } \\
\text { prol de resoluções. }\end{array}$ & 1 & 4 & 0 \\
\hline $\begin{array}{l}\text { 6. Fernandes } \\
\text { et al. }\end{array}$ & 2016 & $\begin{array}{l}\text { COP’s e COPs virtuais como modelo de } \\
\text { aprendizagem aplicado as organizações. }\end{array}$ & 0 & 4 & 0 \\
\hline $\begin{array}{l}\text { 7. Rimá, } \\
\text { Garcia e } \\
\text { Targino }\end{array}$ & 2017 & $\begin{array}{l}\text { Aprendizagem como uma ação interligada } \\
\text { com o mundo, portanto, uma prática social. }\end{array}$ & 1 & 3 & 1 \\
\hline $\begin{array}{l}\text { 8. Wilbert } e t \\
\text { al. }\end{array}$ & 2017 & $\begin{array}{l}\text { Aprendizagem social focada na inovação em } \\
\text { instituições públicas. }\end{array}$ & 1 & 3 & 1 \\
\hline
\end{tabular}


Comunidade de práticas: revisão sistemática em prol das bibliotecas públicas

\begin{tabular}{|l|l|l|c|c|c|}
\hline $\begin{array}{l}\text { 9. Lira, } \\
\text { Araújo e } \\
\text { Duarte }\end{array}$ & 2017 & Aprendizagem como um modelo social & 1 & 2 & 1 \\
\hline $\begin{array}{l}\text { 10. Wilbert, } \\
\text { Dandolini e } \\
\text { Steil }\end{array}$ & 2018 & $\begin{array}{l}\text { Aprendizagem social aplicável a gestão } \\
\text { organizacional. }\end{array}$ & 0 & 3 & 1 \\
\hline $\begin{array}{l}11 \text { Souza e } \\
\text { Souza }\end{array}$ & 2019 & $\begin{array}{l}\text { Aprendizagem social aplicável na gestão do } \\
\text { conhecimento }\end{array}$ & 1 & 3 & 0 \\
\hline $\begin{array}{l}12 \text { Melo, } \\
\text { Moraes e } \\
\text { Costa }\end{array}$ & 2019 & $\begin{array}{l}\text { Aprendizagem como uma ação interligada } \\
\text { com o mundo, portanto, uma prática social. }\end{array}$ & 1 & 4 & 0 \\
\hline
\end{tabular}

Fonte: construção dos autores (2020).

Em prosseguimento a revisão sistemática, sob a discussão dos artigos que versam sobre o conceito de comunidades de práticas, segue as concepções apresentadas no material recuperado na base de dados Capes.

No primeiro artigo de autoria de Campos, Medeiros e Melo (2018), também é possível verificar: a relação do conceito de comunidade de práticas com as implicações inerentes ao campo da gestão do conhecimento; discussão conceitual sobre COP's virtual; estudo de caso mencionado (PROGEP-UFPB); conceito de COP's atrelado não apenas ao intercâmbio de conhecimento, mas também a práticas de desenvolvimento entre os participantes.

No segundo artigo da respectiva base de dados, Fartes (2014), corrobora com os seguintes pontos: adoção basilar sobre o conceito de comunidades de práticas definido por Wenger (1998); elaboração de um estudo de caso em um Centro Federal de Educação Tecnológica (CEFET-IF); elaboração do estudo de comunidade de práticas por intermédio de três etapas: análise documental (relatórios, demais documentos institucionais e ou informais), entrevistas semiestruturadas com os representantes da instituição e anotações de campo.

O terceiro artigo, de Guizardiet al. (2018), não discorre sobre as implicações conceituais da comunidade de práticas, o que se mostra como uma limitação para o presente estudo. Isso se deve ao fato de que o artigo tem por objetivo focar na descrição de estudos de casos de Hackathons na área da saúde (16 práticas são exemplificadas no artigo), apresentando variadas possibilidades de estudo de caso. Destarte, os autores mencionam os Hackathonscomo modelos de comunidades de práticas, tendo em vista a aplicação da aprendizagem como uma prática social em prol de uma solução encontrada em conjunto, porém com pessoas capacitadas no que 
diz respeito a temática a ser resolvida, portanto, que possuem domínio de um determinado conhecimento.

Quanto ao quarto artigo, Ferigato (2018) discute quanto a importância da COP's virtual, porém a literatura não discorre sobre o aporte teórico basilar sobre a COP’s em si, o que é uma limitação para a recuperação do presente trabalho quanto as definições de COP's adotadas na revisão sistemática atual. Ademais, o desenvolvimento de dois estudos de casos (Rede HumanizaSUS e a Comunidade de Práticas de Atenção Básica) ressalta quanto a adoção da COP’s na área da saúde.

O quinto artigo, de Freitag e Santos (2013) por ser um trabalho percussor dos mesmos, apresenta as definições basilares de COP's atrelada a afirmação de Wenger (1998). O estudo de caso descrito aplica o conceito de COP's na elaboração das aulas de ciências do ensino fundamental (10 aulas), de forma a exemplificar a aplicabilidade da COP's em modelos de aprendizagem social interligado com os pressupostos da linguística. Para fins de esclarecimento quanto a definição, adoção ou não, de estudos de casos e pontos pertinentes para a presente pesquisa (pontos fortes) e limitações, segue a tabela 2 abaixo referente a literatura recuperada na base de dados da Capes. A data de publicação também segue a ordem do mais antigo (2013) para o mais recente (2018).

Tabela 2 - síntese da revisão sistemática sobre Comunidade de práticas (base de dados Capes).

\begin{tabular}{|l|l|l|c|c|c|}
\hline \multicolumn{1}{|c|}{ Autor } & \multicolumn{1}{|c|}{$\begin{array}{c}\text { Data da } \\
\text { publicação }\end{array}$} & \multicolumn{1}{|c|}{ Definição de COP's } & $\begin{array}{c}\text { Estudo } \\
\text { de caso } \\
\text { (quant.) }\end{array}$ & $\begin{array}{c}\text { Pontos } \\
\text { fortes } \\
\text { (quant.) }\end{array}$ & $\begin{array}{c}\text { Limitações } \\
\text { (quant.) }\end{array}$ \\
\hline $\begin{array}{l}\text { 1. Freitag e } \\
\text { Santos }\end{array}$ & 2013 & $\begin{array}{l}\text { COP's como modelo de aprendizagem } \\
\text { social. }\end{array}$ & 10 & 1 & 0 \\
\hline 2. Fartes & 2014 & $\begin{array}{l}\text { COP's como modelo de aprendizagem } \\
\text { social. }\end{array}$ & 1 & 3 & 0 \\
\hline $\begin{array}{l}\text { 3. Campos, } \\
\text { Meleiros e }\end{array}$ & 2018 & $\begin{array}{l}\text { COP's como modelo de aprendizagem } \\
\text { social e práticas de desenvolvimento } \\
\text { entre os participantes. }\end{array}$ & 1 & 4 & 0 \\
\hline 4. Guizardiet al. & 2018 & $\begin{array}{l}\text { COP's como modelo de aprendizagem } \\
\text { social. Foco em hackathons na área da } \\
\text { saúde. }\end{array}$ & Aplicação da COP’s na área da saúde. & 16 & 1 \\
\hline 5. Ferigato
\end{tabular}

Fonte: construção dos autores (2020). 
Diante da revisão explicitada acima pela base de dados Brapci e Capes (tendo em vista que a base de dados Scielo recuperou duplicatas), cabe adentramos em alguns fatores que evocam como a COP’s é compreendida, aplicada, além de desvelar características comuns desse modelo.

A definição da COP’s como um modelo que se relaciona com os pressupostos da gestão do conhecimento é visível em 10 dos 12 artigos recuperados na Brapci. A base de dados Capes, por ser mais extensa e não se apresentar como uma base especializada nas áreas da informação (Biblioteconomia, Arquivologia, Museologia, Ciência da Informação e afins), possibilitou a recuperação de artigos que não necessariamente evocam essa relação. Contudo a revisão sistemática em questão reforça o quanto as COP's e sua definição elementar interagem a aprendizagem de viés social ao intercâmbio de experiências, portanto, conhecimento.

Quanto a elaboração de estudos de casos, a grande maioria da literatura recuperada apresenta exemplos de empregabilidade das COP's, com exceção dos artigos de número 6 e 10 disponíveis na base de dados Brapci. Todavia, vale ressaltar que o artigo número 4, disponível na base de dados Capes, evoca a possibilidade dos hackathons serem caracterizados como COP’s, porém não discorre, por exemplo, sobre os indicadores básicos que compõem uma COP, tal como registrado por Melo, Moraes e Costa (2019). Em aditamento, algumas empresas não foram identificadas na literatura, seja por implicações de ordem ética, dados de seu funcionamento e afins.

No tocante ao desenvolvimento das COP's, é conspícuo o uso desse modelo em ambientes virtuais, em grande parte da literatura, sendo os artigos de número 1, 3, 5, 6, 7 e 12 (Brapci), mais o artigo de número 4 recuperado na Capes. Em segundo lugar, a literatura demonstra que as COP’s são compreendidas não apenas no modelo virtual, mas precisamente aplicado nas empresas, tal como consta nos artigos de número 3, 6 e 10 (Brapci). Em terceiro lugar, há dois artigos que apresentam a COP’s aplicável na área da saúde, tal como consta nos artigos de número 4 e 5 recuperados (Capes). Em quarto e quinto lugar, temos um artigo que discute sobre as COP's no ambiente educacional, como é o caso do artigo de número 5 (Capes) e ambiente da biblioteca, exemplificado pelo artigo de número 10 (Brapci).

Assim sendo, é mister alguns dados quanto à definição de COP’s empregada pelos autores. A COP's como um modelo de aprendizagem social, intercâmbio de experiências é adotada pela maioria dos artigos recuperados. Entretanto, alguns detalhes são aparentes e 
passíveis de reflexão. O artigo de número 5 (Brapci) ressalta que o objetivo da COP’s é a resolução de problemas, de forma que o simples intercâmbio de experiências em prol do desenvolvimento de pessoas, grupos e instituições não é evocado como uma justificativa por si, ou seja, o uso da COP’s se deve a necessidade de uma resolução de problemas, não sendo algo adotado como parte integrante do ciclo de operações de uma determinada instituição.

Em contraponto, o artigo de número 8 (Brapci) endossa a formação das COP's com o intuito de prover inovação, dito de outra forma, têm-se pessoas, formação de um grupo que age não necessariamente para resolver problemas de uma determinada instituição, mas sim, de prover avanços, melhorias, desenvolvimento em questões que não necessariamente apresentam percalços para os participantes da COP's. Os autores afirmam que a inovação e COP’s são modelos entrelaçados e benéficos, aplicável nas diversas tomadas de decisão de uma instituição e resultam não apenas em melhora nos processos institucionais, mas também em novos produtos (Wilbert et al., 2017).

Em adendo as singularidades de COP's verificas na revisão sistemática, houve três artigos, de número 3, 4 e 5 (Capes) que aplicam o modelo de COP’s com o viés que não necessariamente apresenta pessoas capacitadas, adequadas, expertises, necessárias para o exercício de tomadas de decisão e resolução de problemas. Ao contrário, os autores desses artigos ressaltam que o uso das COP's também pode ser aplicável para dar "visibilidade ao desconhecimento", prover um período de intercâmbio das dificuldades, levantar questões que podem ser solucionadas pelos participantes, seja por intermédio de soluções externas (contratação de especialistas, empresas etc.) ou mesmo o próprio desenvolvimento da aprendizagem social, no qual os integrantes aprendem entre si e promovem a construção do conhecimento.

As COP's servem às bibliotecas públicas porque elas se convertem em espaços de discussão e troca que permite a aprendizagem em diferentes dimensões. O compartilhamento e intercâmbio de informações e experiências, de forma voluntária, acaba fortalecendo os sujeitos que participam, e, ainda, provem benefícios para as comunidades as quais as bibliotecas públicas estão inseridas. Esse método visa a troca de informação e conhecimento, como o mencionado, busca fortalecer e sustentar a própria comunidade, como também as instituições e agentes, em prol da positivação e afirmação de uma cultura dinâmica, que se desenvolve por intermédio de processos dialógicos como aponta Buber (2014). 
Snyder, Wenger e Sousa Briggs (2003 - 2004) ao reafirmarem as dimensões ou pilares que estruturam as COP's ressaltam que o domínio se refere ao grupo que compartilha de uma paixão ou interesse comum; a comunidade se constrói a partir de interações e relações visando o aprendizado e o compartilhamento de informações; e, a prática nada mais é do que o repertório construído pelos participantes da comunidade que se liga à prática compartilhada. Dito isto, podemos inferir que essas comunidades objetivam a distribuição de informação, resolução de problemas, aprendizado e troca de conhecimentos teóricos e práticos.

Wenger (2002) alerta que esse tipo de método deve ter cunho informal e intencional; deve permitir aos praticantes gerenciar o conhecimento que precisam; deve propiciar a criação, conexão entre aprendizagem e desempenho das funções exercidas; e, ainda, não se limitam pelas conexões organizacionais e restrições de quaisquer tipos, como a geográfica.

A comunidade de práticas em bibliotecas públicas que deriva do projeto de extensão supracitado, alocou profissionais e agentes envolvidos com a rede de bibliotecas populares da cidade de Niterói, no estado do Rio de Janeiro e está em vias de desenvolvimento. Diante do exposto, Wenger (2002) apresenta um guia para cultivar uma comunidade de práticas que se baseia: em educar; escolher um suporte; definir um contexto; encorajar os praticantes; integrar. E, ainda, enfatiza as funções das organizações (instituições) e membros (participantes). Desse modo, conclui-se que a tessitura teórica apresentada pode se estabelecer como fundamentação e, ainda, estrutura e alicerça o trabalho no que tange o desenvolvimento da comunidade de práticas no universo acima descrito em bibliotecas públicas do sistema municipal de Niterói.

Outrossim, as COP's, enquanto ferramentas metodológicas formalizam e dimensionam as necessidades apontando os caminhos a serem percorridos de modo a fortalecer, positivar e auxiliar essas instituições, por via de processos de aprendizagem, mediados pela troca de experiências, convertendo-se em resultados benéficos para as bibliotecas. Além disso, cabe destacar que ao criarem produtos a partir do desenvolvimento das COP's, as bibliotecas evocam processos que as mantém como transformadoras da realidade social por via do empoderamento gerando novas formas de apropriação da educação, cultura, lazer, memória e do exercício da cidadania, tanto por parte dos profissionais, bem como da comunidade que acessa à biblioteca. Isso significa dizer que os processos de aprendizagem, desenvolvimento, apropriação e transformação ocorrem em via de mão dupla - do individual para o coletivo; e do coletivo para o individual, provendo melhores usos a informação e do conhecimento. 


\section{Considerações finais}

A diversidade de transformações sociais, econômicas, políticas, culturais e informacionais têm modificado inúmeras estruturas e instituições, como as bibliotecas públicas. Nas últimas décadas, principalmente no Brasil, problemas e entraves de ordem teórico-prático propiciando a estas instituições uma crise no que tange a sua identidade e representação social enquanto instituição. Pesquisadores e profissionais passaram a se questionar sobre o papel da biblioteca pública. Isso significou obstáculos para compreender o processo de formação, organização e atuação das mesmas, já que não possuem reconhecimento, aderência, tampouco ressonância social. Ademais, uma série de percalços, como a falta de recursos e estruturas governamentais se converteram em barreiras para fomentar seu fortalecimento por meio da criação de políticas públicas eficientes.

As bibliotecas públicas sofrem de descaso e isso modela uma imagem desconectada da realidade vivida pelas comunidades de seu entorno. A partir desse ponto de referência esse artigo apresentou uma revisão sistemática sobre o conceito de COP's ressaltando a sobre a importância da aplicação desta metodologia no contexto das bibliotecas públicas.

Nesse sentido, baseado na troca de informações, conhecimentos e experiências, por meio de reuniões mensais, problemas, questionamentos, resoluções, novas ideias, são resgatadas e se convertem em fonte (memória) para a compreensão das bibliotecas da Rede de Bibliotecas Populares da cidade de Niterói. Todas as ações foram implementadas a partir do modelo metodológico 'COP's descrito por Wenger $(1998,2002)$. O intuito foi consolidar a interação entre a academia (os fazedores de teorias e conceitos) e as bibliotecas (instituições criadoras de práticas) com a finalidade de diminuir o distanciamento entre o discurso teórico e o prático.

Ao iniciar as ações foi imperativo instrumentalizar os agentes envolvidos e por esse motivo começamos a trabalhar com a revisão sistemática do conceito 'COP's', o qual apresentou neste texto como um dos resultados iniciais e parciais da atividade extensionista que, ainda, pode ser configurada como uma atividade de pesquisa, tomando como base todo o levantamento bibliográfico realizado sobre o tema. Essa etapa foi essencial para o projeto fosse mediado por essa metodologia e, para que ela contribua efetivamente para a positivação e afirmação das bibliotecas. Os processos de interação técnico-científica têm contribuído para a formação dos bibliotecários e profissionais envolvidos no projeto; o desenvolvimento de novos conhecimentos; o fomento de novos temas para a pesquisa e extensão; a melhoria das 
bibliotecas no que se refere aos serviços e produtos; a ampliação do entendimento do conceito, função e usos dessas instituições; a identificação de aspectos que levam a ausência da importância da biblioteca para a sociedade, dentre outros avanços.

Esse artigo se coloca na via primeira de demonstração e identificação de como um instrumento metodológico pode estimular, de forma criativa, a aproximação entre a academia, a biblioteca e a sociedade. Com vistas nisso, o projeto vem desenvolvendo cursos de formação, criação de manuais técnicos, modelos de resolução de problemas, seminários temáticos, encontros e reuniões com os agentes, solicitações as instancias do governo local para inserir as bibliotecas no mapa da cidade; conversações sobre políticas públicas. Para o ano de 2020, o projeto se concentra no estabelecimento de alicerces e políticas para a melhoria do funcionamento dessas bibliotecas e, consequentemente, no atendimento das comunidades; a geração de parcerias; a organização de eventos para discutir o tema. E no âmbito da pesquisa os próximos passos se colocam na via da definição de bibliotecas pública e populares por meio também de uma revisão sistemática do conceito. Constado isso, compor um projeto que alinha extensão e pesquisa no âmbito das bibliotecas públicas operacionaliza e endossa a relevância em buscar novas metodologias para compreender os processos e dinâmicas vivenciados nessas bibliotecas de modo a fortalecer a formação de uma nova identidade, positivando essas instituições na tarefa de organizar a sociedade provendo acesso à informação e ao conhecimento, possibilitando câmbios sociais, políticas, econômicos, culturais e, sobretudo informacionais.

\section{Referências}

ACHILLES, Daniele. Comunidade de práticas sobre bibliotecas públicas: informação e intercâmbio de experiências. Rio de Janeiro: UNIRIO, 2018a. (Projeto de Extensão).

ACHILLES, Daniele. Bibliotecas públicas brasileiras: sob a perspectiva da memória e experiência. 2018. 282 f. Tese (Doutorado em Memória Social) - Universidade Federal do Estado do Rio de Janeiro, Rio de Janeiro, 2018.

ALFARO LÓPEZ, Héctor Guillermo. El obstáculo epistemológico y la biblioteca, 2008. In: COLOQUIO DE INVESTIGACIÓN BIBLIOTECOLÓGICA Y SOBRE LA INFORMACIÓN, 25., 2008. Centro Universitario de Investigaciones Bibliotecológicas. Ciudad de México: UNAM, 2008.

ALFARO LÓPEZ, Héctor Guillermo. Estudios epistemológicos de bibliotecología. México: UNAM, Centro Universitario de Investigaciones Bibliotecológicas, 2010. (Teoría y métodos). 
BUBER, Martin. Do diálogo e do dialógico. São Paulo: Perspectiva, 2014.

CARIBE, Rita de Cássia do Vale. A biblioteca especializada e o seu papel na comunicação científica para o público leigo. RICI: Revista Ibero-americana de Ciência da Informação, Brasília, v. 10, n. 1, p. 185-203, jan./jul. 2017. Disponível em:

https://periodicos.unb.br/index.php/RICI/article/view/2511/2239. Acesso em: 2 mar. 2020.

ESCOLAR, Hipólito Sobrinho. Historia de las bibliotecas públicas. 3. ed. Salamanca: Madrid; Fundación Germán Sánchez Ruipérez; Madrid: Pirámide, 1990. (Biblioteca del Libro, C).

GALVÃO, Maria Cristiane Barbosa; RICARTE, Ivan Luiz Marques. Revisão sistemática da literatura: conceituação, produção e publicação. Logeion: filosofia da informação, Rio de Janeiro, v. 6, n. 1, p. 57-73, set. 2019. Disponível em:

http://revista.ibict.br/fiinf/article/view/4835/4187. Acesso em: 14 out. 2019.

GONDAR, Jô. Cinco proposições sobre memória social. In: DODEBEI, Vera; FARIAS, Francisco R. de; GONDAR, Jô (org.). Por que memória social? Rio de Janeiro: Híbrida, 2016.

KORNALEWSKI, Alex Medeiros; FARIAS, Francisco. Ramos. Equívocos e efeitos da memória no âmbito de atuação do bibliotecário: reflexões sob o viés da política de desenvolvimento de coleções. Revista Brasileira de Biblioteconomia e Documentação, São Paulo, v. 15, n. 3, p. 286-307, 2019. Disponível em:

https://rbbd.febab.org.br/rbbd/article/view/1255/1159. Acesso em: 02 mar. 2020.

LOPES, Ilza Leite. Estratégia de busca na recuperação da informação: revisão da literatura. Ciência da Informação, Brasília, v. 31, n. 2, p. 60-71, maio/ago. 2002. Disponível em: http://www.scielo.br/pdf/ci/v31n2/12909.pdf\&gt. Acesso em: 26 jul. 2019.

MOSCOVICI, Serge. Representações sociais: investigações em psicologia social. Petrópolis: Vozes, 2010.

MUELLER, Susana P. M. Bibliotecas e sociedade: evolução da interpretação da função e papéis da biblioteca. Revista da Escola de Bibliotecononomia da UFMG, Belo Horizonte, v. 13, n. 1, p. 7-54, mar. 1984.

SNYDER, W. M.; WENGER, E.; SOUSA BRIGGS, X. Communities of practice in government: levaraging knowledge for perfomace. The Public Manager, Winter, v. 32, n.4, p. 17-21, 2003-2004.

SOARES, Nashila Fernanda et al. Biblioteca comunitária: análise sobre seu conceito, função e papel social. Revista ACB: Biblioteconomia em Santa Catarina, Florianópolis, v. 24, n. 2 , p. 405-419, abr./jun., 2019. Disponível em:

https://revista.acbsc.org.br/racb/article/view/1610/pdf. Acesso em: 02 mar. 2020.

VAZ, Francisco António Lourenço. A função social da biblioteca pública na era da informação. Revista Brasileira de Biblioteconomia e Documentação, São Paulo, v. 16, p. 1- 
16, 2020. Disponível em: https://rbbd.febab.org.br/rbbd/article/view/1301/1200. Acesso em: 02 mar. 2020.

WENGER, Etinne. Cultivating communities of practice: a quick start-up guide for communities of practice. 2002. Disponível em: https://wenger-

trayner.com/project/community-of-practice-start-up-guide/. Acesso em: 10 jan. 2018.

WENGER, Etinne. Communities of practice: learning, meaning and identify. Cambridge: Cambridge University, 1998.

WENGER, Etinne. Communities of practice and social learning systems: the career of a concept. In: BLACKMORE, C. (ed.). Social learning systems and communities of practice. London: Springer, 2010. p. 179-198.

\section{Bibliografia consultada}

INTERNACIONAL FEDERARTION OF LIBRARY ASSOCIATIONS AND INSTITUIONS. Manifesto da Unesco sobre bibliotecas públicas. 1994. Disponível em: https://www.ifla.org/files/assets/public-libraries/publications/PL-manifesto/pl-manifestopt.pdf. Acesso em: 16 jan. 2018.

KOONTZ, C.; GUBBIN, B. Diretrizes da IFLA sobre os serviços da biblioteca pública. Brasília: Briquet de Lemos, 2012. Disponível em:

https://www.ifla.org/files/assets/hq/publications/series/147-pt.pdf. Acesso em: 22 nov. 2017.

SOUZA, Luciana Gonçalves Silva; DUMONT, Lígia Maria Moreira. Exclusão e inclusão digitais em bibliotecas públicas municipais da Região Metropolitana de Belo Horizonte: análise do serviço de acesso à internet disponibilizado pelas instituições para o exercício da cidadania. Encontros Bibli: revista eletrônica de Biblioteconomia e Ciência da informação, Florianópolis, v. 23, n. 52, p. 48-60, maio/ago., 2018. Disponível em:

https://periodicos.ufsc.br/index.php/eb/article/view/1518-2924.2017v23n52p48/36458.

Acesso em: 02 maio 2020.

SUAIDEN, Emir José. Biblioteca pública brasileira: desempenho e perspectivas. 1979. 103p. Dissertação (Mestrado em Biblioteconomia) - Universidade Federal da Paraíba, 1979. Disponível em: https://repositorio.unb.br/handle/10482/12718. Acesso em: 22 jan. 2020. 